\title{
Vestígios indígenas na cartografia do sertão da América portuguesa
}

\begin{abstract}
Glória Kok ${ }^{1}$
RESUMO: Nos três primeiros séculos da colonização da América portuguesa, a cartografia indígena auxiliou no processo de decodificação do espaço convencionalmente chamado "sertão" pelos adventícios. Agentes de colonização da capitania de São Paulo (bandeirantes, soldados, povoadores, burocratas, comerciantes e aventureiros) mapearam cuidadosamente os territórios interiores. A situação colonial, entretanto, impôs uma nova orientação do espaço, bem como classificou os grupos étnicos em categorias distintas, fixas e homogêneas. Nesse processo de conquista da Coroa portuguesa, os grupos indígenas foram gradativamente eclipsados dos mapas, e seus territórios, expropriados.

PAlAVRAS-CHAVE: Populações indígenas. Cartografias. Sertão. Capitania de São Paulo. América portuguesa.

ABSTRACT: During the first three centuries of colonization of Portuguese America, indigenous cartography helped the outlanders to decipher the space that they conventionally named sertão (backcountry). The colonizers in the Captaincy of São Paulo lexpeditions, soldiers, settlers, bureaucrats, merchants, and adventurers) mapped out the hinterland with utmost care. However, because the territory was a colony, such agents reorganized that space and classified the ethnic groups into distinct, fixed and homogenous categories. As the Portuguese Crown moved ahead with its conquest, the indigenous groups were gradually wiped out from the maps and their territories expropriated.

KEYWORDS: Indigenous populations. Cartographies. Sertão. São Paulo Captaincy. Portuguese America.
\end{abstract}

Introdução

\begin{abstract}
1. Doutora em História Social pela USP. Pós-doutoranda no Departamento de Antropologia do IFCH-Unicamp. Pesquisadora do Centro de Pesquisa em Etnologia Indígena do IFCH-Unicamp. E-mail: $<$ kokmartins@uol.com.br>.

2. Ver Laura de Mello e Souza (1997).
\end{abstract}

"Foi nos espaços abertos e nas zonas distantes que se passou boa parte da história da colonização da América."2

Laura de Mello e Souza 
3. Para um estudo mais aprofundado da exploração do sertão pelos paulistas, ver Glória Kok (2004).

4. Cf. Claude Lévi-Strauss (1997, p. 31).

5. Cf. Fernão Cardim (1980, p. 95).
Nos três séculos iniciais do processo de colonização da América portuguesa, o espaço - convencionalmente chamado de sertão pelos europeus - traduzia-se em vastidão desconhecida e imprecisa, à margem dos núcleos de povoamento, das igrejas e do raio de ação da administração colonial. Tratava-se, sobretudo, de territórios de circulação dos povos nativos e, não raro, encontrava-se à mercê das conquistas espanholas ${ }^{3}$.

Do intenso convívio dos habitantes da Capitania de São Paulo com as populações indígenas, seja por apresar os "negros da terra" como escravos, seja através das relações de parentesco firmadas durante a conquista, derivou uma progressiva decodificação dos territórios indígenas, incentivada pelas autoridades portuguesas com o intuito de garantir o domínio dos habitantes e de suas terras.

Técnicas e estratégias complexas, transmitidas pelos nativos aos paulistas, viabilizaram as sistemáticas expedições pelo sertão - bandeiras, monções e levas de povoadores para as fronteiras -, capazes de enfrentar florestas tropicais, descampados, serras íngremes, rios encachoeirados e terrenos pantanosos. Nessas empresas coloniais, as contribuições dos grupos nativos foram imprescindiveis no que se refere a fornecer informações detalhadas não só sobre a topografia e a geografia, bem como outros conhecimentos, necessários à elaboração de mapas, esboços, técnicas de representação e orientação nos caminhos terrestres e fluviais do sertão. Esses conhecimentos integravam a "cartografia indígena", isto é, um acervo de informações espaciais, construído pela memória e enraizado, principalmente, nos sentidos. Seguindo os passos do antropólogo Claude Lévi-Strauss, pode-se dizer que a cartografia indígena inscreve-se numa "ciência do concreto", baseada em modos de observação e de reflexão a partir da "organização e da exploração especulativa do mundo sensivel, em termos de sensivel"4.

Uma cartografia dos sentidos

○ jesuíta Fernão Cardim observa que os sentidos dos índios eram aguçados em demasia, sendo eles semelhantes aos

Bichos do mato, porque entrão pelo sertão a caçar despidos e descalços sem medo nem temor algum. Vêem sobre maneira, porque à légua enxergão qualquer cousa, e da mesma maneira ouvem; atinão muito; regendo-se pelo sol, vão a todas as partes que querem, duzentas e trezentas léguas, por matos espessos sem errar ponto, andão muito, e sempre, de galope, e principalmente com cargas, nenhum a cavalo os póde alcançar: são grandes pescadores e nadadores, nem temem mar, nem ondas, e aturão um dia e noite andando, e o mesmo fazem remando e às vezes sem comer ${ }^{5}$.

Destros na observação do sol, dos astros e dos rastros, o sentido de orientação dos "naturais da terra" era depurado, além de serem dotados de uma 
aguda capacidade de percepção da geografia, da topografia e da natureza da América portuguesa. Gabriel Soares de Sousa, rico proprietário de terras e de escravos na Bahia do século XVI, notou que os nativos exploravam novos territórios com grande habilidade: "Tem os tupinambás grande conhecimento da terra por onde andam pondo o rosto no sol, por que se governam, com o que atinam grandes caminhos pelo deserto que nunca andaram". Menciona o caso de dois tupinambás que, conduzidos da Bahia ao Rio de Janeiro por mar, daí fugiram e regressaram isoladamente para a sua aldeia, vencendo cerca de 300 léguas por caminhos desconhecidos ${ }^{6}$.

Para o historiador Jaime Cortesão, os ameríndios desenvolveram uma "visão telescópica", capaz de entrever vultos ou acidentes à distância, e uma "memória visual" extraordinária". Detentores de "aguda consciência do espaço geográfico" aliada a uma "notável capacidade de representar"8, os índios transmitiram aos sertanistas a capacidade de orientação e a habilidade cartográfica, registrada por muitos estudiosos.

$\bigcirc$ médico naturalista alemão Karl Von den Steinen, por exemplo, conta que um capitão da etnia Suiá desenhou na areia parte do curso do Alto Xingu, com numerosos afluentes, indicando treze tribos ribeirinhas?. Esboços minuciosos da localização de tribos dos Tapirapé, desenhados por um carajá, foram utilizados pelo etnólogo Fritz Krause como fonte para a localização de tribos do sertão do Mato Grosso ${ }^{10}$.

Enviado pela Metrópole para explorar a Amazônia e o Alto Paraguai de 1783 a 1792, o doutor Alexandre Rodrigues Ferreira conta que um índio morador no Rio Branco usou uma corda de piaçá para formar o tronco do rio principal com os seus tributários e, com nós, sinalizou as aldeias de índios. $\mathrm{Na}$ mesma região, um índio macuxi desenhou o mesmo rio na areia com um bastão. naturalista convidou-o a repetir o traçado no papel, ao que ele se prestou, riscando um mapa, "onde as cordilheiras eram marcadas por sucessivas séries de ângulos mais ou menos agudos e as malocas dos gentios, por círculos maiores ou menores"11, convenções semelhantes às utilizadas atualmente.

capuchinho francês Yves d'Évreux, arguto observador dos costumes dos Tupinambá do Maranhão, informa: "Quanto à memoria elles a possuem muito feliz, porque lembram-se sempre do que viram e ouviram com todas as circunstancias do lugar, de tempo, das pessoas, quando o caso se disse ou se executou, fazendo uma geografia ou descrição natural com a ponta dos seus dedos na areia, do que estão contando"12.

Veredas indígenas

Desde o período pré-cabralino, as rudimentares veredas indígenas significavam artérias de comunicação entre tribos tupis-guaranis. Referindo-se às vias de comunicação entre os diversos grupos guaranis, Natalício Gonzalez escreveu:
6. Cf. Gabriel Soares de Sousa $(1987$, p. 319).

7. Cf. Jaime Cortesão ([1965?], p. 28).

8. Cf. Jaime Cortesão (1958, p. 18).

9. Cf. Sergio Buarque de Holanda (1994, p. 23).

10. Idem, ibidem.

11. Cf. Jaime Cortesão ([1965?], p. 28).

12. Cf. Yves d'Évreux (1929, p. 122). 
13. Natalício Gonzalez. Apud Edmundo Zenha (1970, p.7778).

14. Cf. Sérgio Buarque de Holanda (1994, p. 26).

15. Cf. Ernani Silva Bruno (1966, p. 18).

16. Os apetrechos eram "instrumentos de cozinhar e moquear, canoas, choças, redes, cabaças de apanhar água". Cf. Sérgio Buarque de Holanda (1990, p. 17).

17. Cf. Jaime Cortesão (1955, p. 16).

18. Cf. Pasquale Petrone (1995, p. 35).

19. Cf. John Monteiro (1994, p. 61).

20. Cf. Sérgio Buarque de Holanda (1996, p. 76).

21. Cf. André João Antonil ([s. d.], p. 284).

22. Cf. Sérgio Buarque de Holanda (1994, p. 27)

23. Cf. Teodoro Sampaio (1902, p. 493-494).

24. Esclarece Jaime Cortesão: "Os 'cosmógrafos' aqui equivale a cartógrafos e tanto mais quanto, por via de regra, nos séculos Quinhentos e Seiscentos, quando estes assinavam os seus mapas e principalmente os atlas, se intitulavam, cada um e a seguir ao nome, - 'cosmógrafo de S. Majestade”. Cf. Jaime Cortesão (1958, p. 40).

25. Idem, ibidem.
Otras veces actuam [os grupos guerreiros] como el más eficaz vehiculo del naciente y esporádico comercio de las tribus. Una preciosa red de caminos completava el sistema de las comunicaciones. Senderos sembrados de ciertas gramillas seleccionadas que ímpiden el nacimiento de otras plantas, mantiene expeditas las comunicaciones entre las diversas parcialidades guaranies a través de las grandes selvas americanas. El correo, el parejhara, que efectua viajes combinadas a distancias regulares, difunde com extraordinaria rapidez las noticias que interessan al destino de las tribus ${ }^{13}$.

No sertão, portanto, as entradas seguiam as apé, veredas indígenas que comunicavam aldeias e povoados. Geralmente, os caminhos primitivos, eram "em regra pouco melhores do que carreiros de antas"14, e constantemente "se tinham de redescobrir e refazer, por olvidadas ou perdidas" 15 . No entanto, esses traçados privilegiavam os rios piscosos e locais de caça abundante, além de serem bem providos com apetrechos utilizados pelos viandantes ${ }^{16}$.

$\bigcirc$ itinerário indígena mais importante foi denominado Peabiru pelos indígenas e, posteriormente, caminho de São Tomé pelos jesuítas. Ligava as "tribos da nação Guarany da bacia do Paraguay coma a tribu dos Patos do litoral de Santa Catarina, com os Carijós de lguape e Cananéia, e com as tribos de Piratininga e do litoral próximo"17. De acordo com Washington Luís, era um caminho "muito batido, com uma largura de 8 palmos, estendendo-se por mais de 200 léguas desde a capitania de S. Vicente, da Costa do Brasil, até as margens do rio Paraná, passando pelos rios Tibagi, Ivaí e Pequeri" ${ }^{18}$. Nas primeiras décadas do século XVII, esse itinerário foi percorrido pelos paulistas à caça do gentio guarani que habitava o sertão dos Patos, no atual estado de Santa Catarina, e o sertão dos Carijós, nas terras que margeavam o rio Paranapanema ${ }^{19}$.

$\bigcirc$ "marchar à paulista"20, hábito comum nas bandeiras, pressupunha andar a pé muitas léguas, como faziam os índios: sem o uso de calçados, da madrugada "até o meio-dia, e quando muito até uma ou duas até às três horas da tarde"21. Em carta escrita 1676, o cabildo de Assunção do Paraguai declara: "los Portugueses que hasta aquí se an visto son todos mansevos descalsos de pié y pierna con escopetas y alfanges" 22 .

Como a língua-geral era predominante nas bandeiras, os paulistas acabaram difundindo nomes tupis em suas andanças pelo sertão. "As levas que partiam do litoral a fazer descobrimentos falavam, no geral, o tupi; pelo tupi designavam novos descobertos, os rios, as montanhas, os próprios povoados que fundavam e que eram outras tantas colônias espalhadas por sertões, falando também o tupi e encarregando-se naturalmente de difundi-lo"23, explica Teodoro Sampaio. Referindo-se ao curso do Paraguai, escreve: "E finalmente que eram infinitas as nações que habitavam as margens deste rio, à maneira do Grão-Pará. Tudo isto referiam aqueles índios aos nossos cosmógrafos ${ }^{24}$ e tudo o tempo, descobridor das coisas, tem mostrado claro" 25.

Nas jornadas do sertão, os ameríndios marcavam os troncos dos grossos arvoredos para sinalizar os caminhos, processo comum a todo continente 
americano, chamado ibapaá, caapeno, cuapaba ou caapepena ${ }^{26}$. De acordo com o jesuíta João Daniel:

Governam-se (os índios) pelo sol, lua e estrellas. E só quando os matos são pouco limpos, por baixo exvi dos arbustos, que nascem à sombra dos arboredos, é que costumam fazer um signal a que chamam caapeno, que significa mato quebrado, e é o irem quebrando com a mão alguns raminhos daquelles arbustos, que vão deixando semi-quebrados e dependurados, para que na volta sirvam de balisas e mostradores; que thes apontem o caminho pelo qual tornem a sahir ao mesmo lugar ${ }^{27}$.

Incorporada pelos sertanistas, a prática de sinalizar e marcar pontos de orientação - pedras inscritas, árvores gravadas, cruzes toscas, ranchos, queimadas e sepulturas - sugeria o esforço de tornar familiar e decifrável o ambiente hostil do sertão. Cruzes toscas e rudes inscrições em homenagem ao monarca português simbolizavam o conjugado esforço de dilatação da fé e fortalecimento da Coroa lusitana na conquista dos novos territórios ${ }^{28}$. Estratégia semelhante foi utilizada pelos engenheiros militares nas expedições científico-demarcatórias, como mostra o mapa de André Vaz Figueira de 1754 (Figura 1).

O piloto José Ignacio, que acompanhava o sargento-mor Francisco de Souza e Faria, testemunha a grande quantidade de cruzes avistadas, que provavelmente serviam para orientar os viandantes em seus itinerários. "Logo da saída do mato ao norte distância de um quinto de légua pouco mais ou menos se vê uma cruz ao pé duma lomba [...] Passada esta lomba caminho de noroeste, e distância duma légua se encontra outra cruz em um alto que se chama Arraial Grande, de onde continuando ao norte achamos outras cruzes a pouca distância umas das outras" 29 .

Nas cabeceiras do córrego Turvo, a expedição do capitão-mor Luiz Borges Pinto - depois de uma investida contra um quilombo de negros, que resultou em morte de quatro quilombolas e no aprisionamento dos demais marcou com uma cruz a cabeceira do córrego Poço Grande "para mostrar algumas faíscas d'ouro" 30 . Já em meados do século XVIII, a primeira expedição militar ao Tibagi, ao se deparar com os saltos do rio Registro e com o fim dos mantimentos, deixaram no ponto de regresso da expedição "hua Crus lavrada em hû pinheiro e sobre a maior queda que fas o rio em hûa grande pedra que vira para o Nordeste lavrada outra Com hû picão, e por baixo as letras V.R.P, e em outra pedra, onde finda o rio navegável" ${ }^{\prime \prime 1}$. Deste modo, erguiam-se cruzes pelos itinerários dos sertanistas com o intuito de indicar o caminho a seguir, os acidentes topográficos, a presença de ouro, ou, simplesmente, a morte de algum desafortunado que pereceu longe de sua vila.

No início do século XVIII, com a decadência das bandeiras e o descobrimento dos placers auríferos de Goiás e Mato-Grosso, a penetração do sertão infiltra-se, de modo definitivo, pelas "estradas que andam"32: os rios Tietê, Paraná, Paraguai e seus afluentes.
26. Cf. Ver Sérgio Buarque de Holanda (1994, p. 1920).

27. Cf. João Daniel (1841, p. 42).

28. Escreve Laura de Mello e Souza: "a dilatação da fé, colonização e fortalecimento do poder monárquico sempre aparecem associados". Ver Laura de Mello e Souza (1986a, p. 33-34).

29. Piloto José Ignácio. Apud Affonso d'E. Taunay (1981a, p.149).

30. Cf. Luiz Borges Pinto. Apud Affonso d'E. Taunay (1981a, p.163

31. Cf. Arquivo do Estado de São Paulo (1895, v. 4, p. 3738).

32. Cf. Basílio de Magalhães (1944, p. 274-275). 


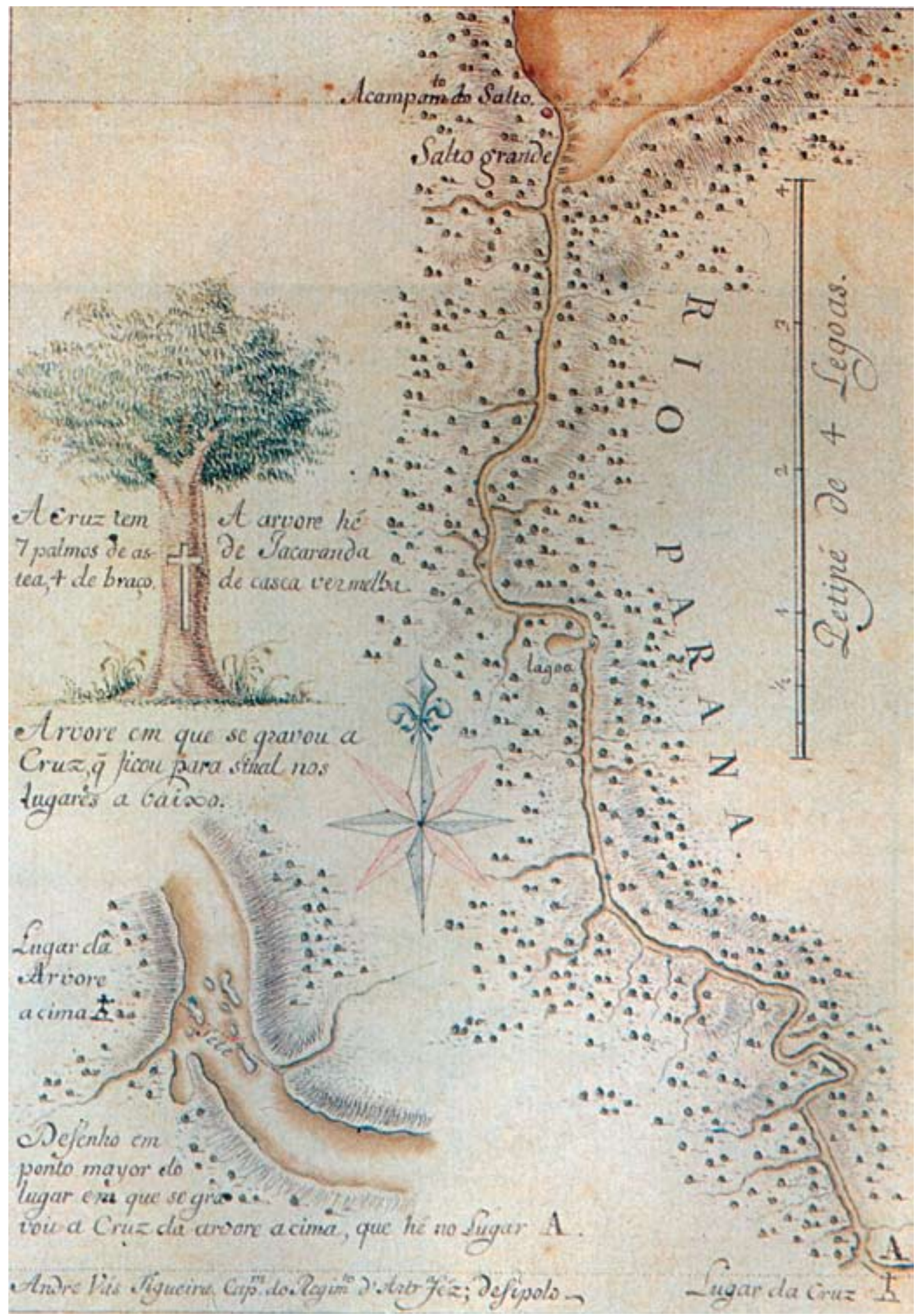

Figura 1 - A prática de sinalizar e marcar pontos de orientação - pedras inscritas, árvores gravadas, ranchos e sepulturas - traduziam o esforço de tornar familiar e decifrável ao viandante o ambiente hostil do sertão. Plano do Salto Grande do Rio Paraná e desenho de um jacarandá, onde foi gravada uma cruz para sinal, feitos por André Vaz Figueira em 1754. In: Mapa, 1993, p. 289. 
Em 1725, uma carta dos oficiais da Câmara de São Paulo ao governador Rodrigo César de Menezes afirma que:

Sem a gente parda se não podem fazer os descobrimentos do ouro, por ser só ela a que sabe talar o sertão e navegar os rios, livrando dos perigos que nele se encontram, por causa das muitas cachoeiras e os mais que embaraçam as navegações, sendo a gente parda a que sustenta os sertanistas assim pelos rios como pela terra, pelo largo conhecimento que têm de tudo o que pode servir de alimento ${ }^{33}$.

Nos caminhos fluviais, os paulistas conservaram praticamente intactas as técnicas indígenas de construção de embarcações e de mareagem pelos rios encachoeirados. Em 1628, Luiz Céspedes y Xeria fez uma viagem de São Paulo à Assunção, onde assumiria o cargo de governador. Depois de ter andado quarenta léguas por "tierra y a pie, por ser camiño fragosissimo que no se puede andar de otra manera con ynfinitos trabajos de liubias y rios" 34 , atravessou dezoito vezes o rio Tietê e chegou a um porto onde mandou construir grandes embarcações. Fabricou três canoas, uma delas com dezessete metros e sessenta centímetros de circunferência, dezesseis metros e meio de comprimento e um metro de trinta de dois centímetros de boca, capaz de abrigar cinqüenta índios remeiros, outros tripulantes e mantimentos ${ }^{35}$.

Depois da descoberta das minas de Cuiabá, em 1718, inaugurou-se a fase das jornadas fluviais denominadas monções ${ }^{36}$, responsáveis pelo comércio - sobretudo armas, sal, escravos, vinho, azeite, aguardente e artigos manufaturados - de São Paulo com Cuiabá e Mato Grosso. As monções geralmente partiam nos meses de março e abril, período em que os rios se encontravam cheios, minimizando os riscos da navegação. Do porto de Araritaguaba, hoje Porto Feliz, desciam normalmente o Tietê até a foz, seguiam o curso do atual Paraná, subiam - Anhanduí-Guaçu até o Paraguai. De lá alcançavam o São Lourenço para finalmente chegar em Cuiabá.

As frotas de comércio indicavam a existência, mesmo naqueles remotos sertões, de uma sociedade hierarquizada. $\bigcirc$ conhecimento das técnicas de navegação, acumulada durante os anos, e uma acurada capacidade de observação do movimento das águas, da localização das pedras e do curso dos rios conferiram aos pilotos das canoas um estatuto diferenciado dos demais marujos, visível no luxo das vestimentas. Quando D. Antônio Rolim de Moura, o Conde de Azambuja, viajou de São Paulo a Cuiabá, no ano de 1751, embarcou na primeira canoa junto com o "Guia do caminho todo muito bem vestido com farda azul, e chapeo de plumas tudo agaloado, este hia piloteando, levava seis remeiros com vestia, e calção encarnado, e carapuça, ou barrete, com as armas de S. Excellencia abertas em prata" ${ }^{\prime 37}$.
34. Affonso de Taunay (1922a, p. 112).

35. Idem, ibidem.

36. Segundo Sérgio Buarque de Holanda (1994, p. 137), a palavra monção era de procedência árabe e propagouse entre os paulistas até o segundo decênio do século XVIII. Designava, originalmente, os ventos alternados que determinavam as épocas de navegação no oceano Índico.

37. Cf. RELAÇÃO da chegada... (1988, p. 245). 
38. Cf. Arquivo do Estado de São Paulo (1895, v. 22, p.185).

39. Gervásio Leite Rebello. Apud Affonso d'E. Taunay (1981b, p. 109).

40. Dr. Diogo de Toledo Lara e Ordonhes. Apud Affonso d'E. Taunay (1981b, p. 229).

41. D. Antonio Rolim. Apud Affonso d'E. Taunay (1981b, p.199).

42. Idem, p. 206.

43. Cf. Theotônio José Juzarte (2000, p. 38).

44. Essa expedição ocorreu no ano de 1628. Ver Affonso d'E. Taunay (1922a, p. 114).

45. Cf. Sergio Buarque de Holanda (1990, p. 67).

46. Cf. Affonso d'E. Taunay (1922a, p.111).

47. Cf. Sérgio Buarque de Holanda (1996, p. 6).
Os homens de posse e as autoridades não tinham apenas o privilégio de embarcar na primeira canoa em que ia o guia principal, mas podiam encomendar canoas especiais, que thes garantissem a qualidade do serviço da mesa pelo tempo que a monção durasse.

Em 1727, Rodrigo César de Meneses, governador da capitania de São Paulo, saiu de Araritaguaba levando consigo um séquito de noventa pessoas, uma armada de 308 canoas com mais de três mil homens ${ }^{38}$ e canoas de copa e cozinha à sua disposição ${ }^{39}$. O mesmo ocorreu na monção de 1785, em que viajava o juiz Dr. Diogo de Toledo Lara e Ordonhes. Graças à indubitável qualidade de dois cozinheiros, o juiz confessa: "comemos com gosto, e parece que estávamos em povoado, não faltava nada" 40 .

Nas grandes monções, figuravam canoas pequenas a que chamavam montarias. Na viagem do conde de Azambuja, três canoas dessas tomaram a vanguarda da monção. Na maior parte do tempo, seus tripulantes ocupavam-se em pescar e caçar "longe do ruído que faz a tropa" 4 . Outra função dos integrantes dessas canoas era limpar, a golpes de machado, os galhos e troncos de árvores que obstruíam a passagem pelos caminhos fluviais. Apenas no rio Camapuã, o conde de Azambuja contou mais de oitenta paus que foram cortados ${ }^{42}$. Quando isso não era possível, os tripulantes das canoas de montaria punham-se a gritar para alertar os navegadores da retaguarda sobre os perigos e dificuldades entrevistas no rio.

Independente do status do viajante transportado, pilotos e remadores tinham o hábito de, na travessia de cachoeiras e varadouros, despir-se "pela razão de que dando uma destas embarcações em alguma pedra, perdendo o equilíbrio da correnteza, fogem estes homens nadando"43. Já no século XVII, no longo percurso do rio Tietê que compreende o salto do Avanhandava até o salto do Itapura, todos os tripulantes da expedição de D. Luís de Céspede y Xeria, futuro governador de Assunção, optaram por ficar nus ${ }^{44}$. Há indícios de que foram frequentes as deserções entre os remadores. Consta que muitos remadores, despidos da cintura para cima, "costumavam untar-se de gordura, a fim de não poderem ser facilmente agarrados quando tentassem fugir" 45 .

No século XVII, os remadores eram quase todos indígenas, principalmente carijós. A expedição de Céspede y Xeria, por exemplo, conduzia seis criados, cinco índios e índias, e quarenta remadores indígenas ${ }^{46}$. No século $X V I I I$, entretanto, o influxo de escravos negros e o aumento de miscigenados alteraram a composição dos mareantes das monções. Embora nesse período o contingente indígena ainda predominasse entre os remadores, cresceu, de forma significativa, o número de africanos e de mamelucos desocupados. De acordo com a análise de Sérgio Buarque de Holanda, em cada canoa de monção de povoamento, a relação entre escravos e livres seria de oito para um ${ }^{47}$.

Hercules Florence, integrante da monção do cônsul Langsdorff, que deixou a cidade de Porto Feliz em 1826, indispôs-se com o comportamento desregrado dos dezoito remadores da tripulação que fizeram pouso na freguesia da Santíssima Trindade, situada na margem esquerda do rio Cuiabá. "Com 
grande custo embarcamos hoje nossos remadores. Uns estavam completamente embriagados, outros não queriam deixar os parentes ou amigos, que haviam acudido por terra a dizerem-thes novamente adeus. Esta gente recebe a metade do salário adiantado e, enquanto tem um real, bebe a mais não poder ou gasta tudo com mulheres." 48 . Assim, no século XIX, essa gente desenraizada, inconstante e indisciplinada compunha a camada fluida e marginalizada da sociedade paulista.

percurso fluvial até a fronteira de lguatemi

A ameaça do avanço castelhano pela América portuguesa, notadamente pelas regiões de Minas Gerais e da então recente capital do Estado do Brasil, o Rio de Janeiro (1763), levou o ministro dos Negócios Estrangeiros e da Guerra, Sebastião José de Carvalho e Melo, futuro Marquês de Pombal, a promover, em 1770, a demarcação e ocupação das fronteiras. Tal empresa ficou a cargo do governador da capitania de São Paulo D. Luís Antônio de Sousa Botelho Mourão, o Morgado de Mateus.

Dilapidando os cofres públicos e particulares, as autoridades coloniais realizaram verdadeiras "sangrias" na população da capitania de São Paulo para povoar as fronteiras. A ocupação da Praça de N. Senhora dos Prazeres, na margem esquerda do rio Iguatemi, região fronteiriça entre o Paraguai e as terras do Mato Grosso, era um dos alvos da expansão portuguesa. Para Laura de Mello e Souza, "numa colônia em que as fronteiras ainda eram móveis e provisórias, cujos limites só seriam traçados em 1777 - mas que, até o século XX, seriam redefinidas - a expansão e as frentes de povoamento eram extremamente importantes" 49 .

Em 10 de janeiro de 1768, Teotônio José Juzarte, ajudante do Regimento de Dragões Auxiliares da Capitania de São Paulo, era o principal responsável pela escolta do comboio que partiria transportando mantimentos e uma segunda leva de povoadores do porto de Araritaguaba. Juzarte tinha a obrigação de fiscalizar a construção das canoas e de preparar o almoxarifado da expedição: armas e munições, móveis, roupas, medicamentos, foices, machados e enxadas ${ }^{50}$. Às vésperas da partida, a organização da expedição, que vinha sendo preparada há mais de dois anos, ainda se mostrava bastante caótica. Juzarte queixou-se das "impertinências, trabalhos incômodos" do povo, "uns adoecendo, outros pedindo várias coisas supérfluas para eles, e suas famílias, outros pedindo licença para se ausentarem". As mulheres, principalmente, "nunca jamais são boas de contentar, umas com dores de barriga, outras pejadas, e na hora do parto"51. Uma índia bororo, sentindo as dores do parto, retirou-se do "tumulto da gente" "e ao pé de um matinho que tem uma Prainha aí pariu, e depois do parto ela pegou a criança, e saiu para fora e no dia sucessivo andava sem moléstia alguma"52.
48. Cf. Hercules Florence (1977, p. 30).

49. Cf. Laura de Mello e Souza (1986b, p. 82).

50. Cf. Teotônio José Juzarte (2000, p. 23).

51. Idem, p. 27

52. Idem, p. 28 
53. Idem, p. 22

54. Cf. Affonso de E. Taunay (1922b, p. 37).

55. Cf. Teotônio José Juzarte (2000, p. 24).

56. Idem, ibidem.

57. Idem, ibidem.

58. Idem, ibidem.

No dia 13 de abril de 1769, Juzarte partiu de Araritaguaba, comandando trinta e seis canoas - que transportavam mais de setecentos homens, mulheres e crianças de todas as idades, trinta soldados de linha, gente de mareação e equipagem ${ }^{53}$. Além de um diário, Juzarte recebeu ordens de $\mathrm{D}$. Luís de Sousa para a execução de uma planta de "todos os rios, todos os paizes, todas as causas mais notáveis que se tiverem descobrindo" 54 . Desenhou 65 prospectos do caminho fluvial.

Antes de embarcarem, as pessoas confessaram e receberam sacramentos, pois, ao longo dos dois meses de duração da viagem até lguatemi, não encontrariam igrejas nem sacramentos. No momento que antecedeu a partida, o pároco benzeu a expedição e, ajoelhando-se sobre o barranco do rio, entoou a ladainha para Nossa Senhora, benzeu todas as canoas e largou cada uma delas em direção ao sertão, nas mãos da "divina Providência"55.

Cada canoa media de cinquenta até sessenta palmos de comprimento, uma boca que variava de cinco a sete palmos e com capacidade para oito homens, oito remos, quatro varas, uma coberta de lona, pólvora, bala, machado, foices, enxadas e armas de fogo.

Viajavam em pé, o piloto na frente, o proeiro e cinco ou seis remeiros. Os tripulantes, sentados sobre cargas, navegavam a céu aberto com a água beirando um palmo da borda. Essa característica era tão marcante que Juzarte a representou em uma de suas estampas (Figura 2). Aqueles que podiam arcar com a despesa solicitavam uma desconfortável barraca de baeta vermelha forrada de linhagem, para duas pessoas, armada temporariamente na viagem.

A navegação ocorria diariamente, quando não havia neblina, das oito horas da manhã às cinco horas da tarde. Mas, muitas vezes, o sol aparecia somente por volta do meio dia. Todos remavam ao mesmo tempo, numa atividade bastante ritmada. Segundo Juzarte, cabia ao proeiro "meter o remo na água e dar uma pancada com o calcanhar no lugar onde pisa, de sorte que este estrondo serve de compasso para que todos ao mesmo tempo metam os remos na água, e a força seja igual, e assim continuamente seguem todos os mais das outras canoas que fazem uma butha surda e continuada" 56 .

Uma canoa das grandes, bem armada, servia de "capitânia" para as demais e destacava-se pela bandeira de popa, com as armas portuguesas. Essa canoa partia antes das outras, levando um guia, "um homem dos mais práticos e inteligentes daquele sertão, ao qual todos os mais pilotos obedecem"57.

Os mantimentos do "quotidiano sustento" eram acomodados em sacos cilíndricos de cinco ou seis palmos de comprido. Durante a viagem, a alimentação era à base de feiião, farinha de mandioca ou de milho, toucinho e sal, acrescida, esporadicamente, de peixe, caça ou mel de pau.

Na hora do pouso, abria-se uma clareira para acomodar a gente na terra, enquanto as canoas ficavam na água presas com cipó. Cada um acendia o fogo, porque, durante "a dita viagem se costuma cozinhar à noite, o que se há de comer no outro dia, porque, se não pode acender fogo ao jantar se come frio o feijão que ontem se cozinhou" ${ }^{\prime 58}$. As redes eram estendidas entre os troncos e 


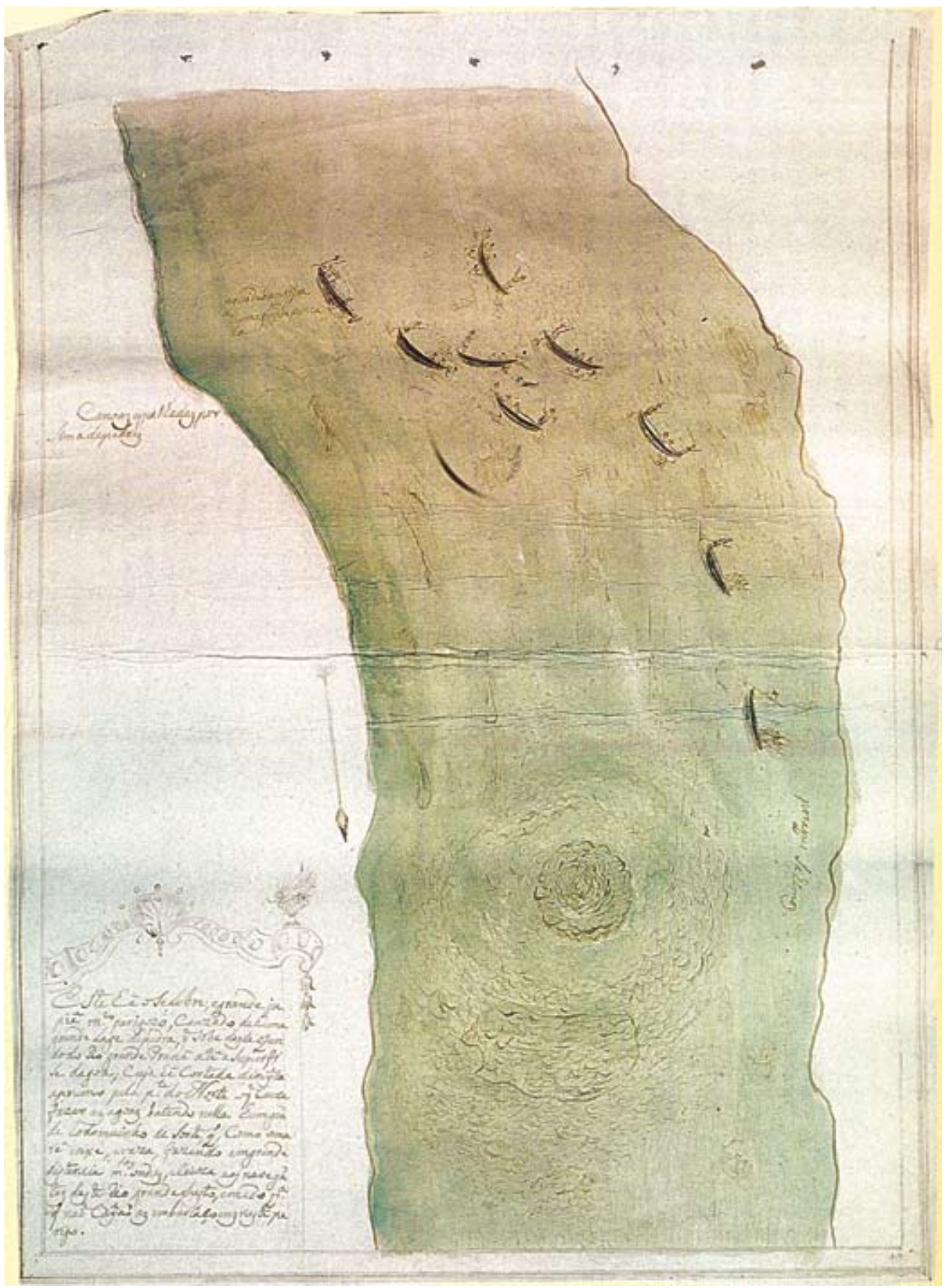

Figura 2 - Teotônio José Juzarte. Este é o célebre e grande Jupiau, muito perigoso, causado de uma grande laje de pedra, que sobe desde o fundo do rio Grande Paraná até a superfície da água; cuja é cortada direita a prumo pela parte do Norte o que causa fazer as águas batendo nela um grande rodamoinho da sorte que como a maré enche e vaza, fazendo em grande distância muitas ondas, causa aos navegantes deste rio Grande susto e medo para que não caiam as embarcações neste perigo, 1769. Fonte: SOUZA; MAKINO, 2000, p.397. 
59. Idem, p. 40.

60. Idem, p. 54

61. Idem, ibidem.

62. Idem, p. 55. cobertas por mosquiteiros de linhagem, que, por sua vez, eram cobertos por baeta, para não respingar água.

À medida que os dias passavam, entretanto, os viajantes sentiam o desânimo pesar. Só no curso do rio Tietê, desde Araritaguaba até o rio Paraná, numa distância de cento e trinta léguas, Juzarte levou vinte e cinco dias de viagem e contou quarenta e seis cachoeiras, além de inúmeras itaipavas muito perigosas. Alguns desses acidentes eram mais decisivos para a travessia. O Salto de ltapura, por exemplo, foi representado por Juzarte em duas escalas, em estampas distintas, de modo a detalhar a dificuldade oferecida pelo último dos grandes obstáculos a transpor no rio Tietê antes de sua foz no rio Paraná (Figuras 3 e 4).

Obstáculos naturais à navegação, como pedras, corredeiras e cachoeiras, demandavam um esforço enorme dos viajantes. Muitas vezes, eram obrigados a desembarcar e, abrindo picadas pelo mato espesso às margens do rio, carregavam canoas e mantimentos às costas. Ficavam, assim, sujeitos aos ataques de mosquitos, bernes, carrapatinhos, moscas, cobras, formigas e marimbondos, sem contar os cortes e arranhões causados pelos galhos das árvores. Dois dias foram empregados na travessia do gigantesco salto de Avanhandava, que em português quer dizer "onde correm os homens" 59 . Todas as embarcações foram descarregadas, passaram-se as cargas para a parte de baixo do Salto e, abrindo-se um caminho no mato, puseram as canoas em cima de paus torados para puxar as embarcações. Na estampa relativa ao grande salto do Avanhandava, Juzarte, além de figurá-lo, detalhou o "varador por terra" e os acampamentos, indispensável à transposição da cachoeira (Figura 5).

Descendo o rio Grande do Paraná, que em português significa "grande mar", havia o risco de contrair enfermidades, por causa das águas pestilentas represadas, dos castelinhos de espuma denegridos e do clima doentio. Neste trecho, o perigo das cachoeiras era substituído pelo "bafo de vento", que fazia ondas e forçava o desembarque em terra e a retirada da carga ${ }^{60}$. Procurava-se, então, fazer pouso longe dos "vapores maus do Rio Grande e de suas tormentas" 61 .

Durante a viagem, crescia a cada dia o número de doentes. Tendo morrido nas margens do rio Paraná, a filha de um povoador foi colocada dentro de um caixão de toucinho e embarcada numa canoa, para ser enterrada em Iguatemi. Como o vento, a fome e vários imprevistos retardavam a viagem, os povoadores e homens de marinha se convenceram de que a causa de tantas adversidades era a defunta que ia no caixão. Resolveram, contra a vontade dos pais da menina, enterrá-la no sertão ermo, em uma itha do rio.

Além das doenças, o principal perigo do rio Paraná era atravessar um rodamoinho que, de uma margem a outra, revolvia continuamente as águas, formando ondas. O centro era como um sorvedouro, pois, "apanhando uma embarcação, ou outra qualquer cousa, a faz andar à roda, e em um momento a atrai a si, que sendo embarcação a faz precipitar ficando a popa no ar, metendo-se a proa pelas águas abaixo donde não torna a aparecer" 62 . 


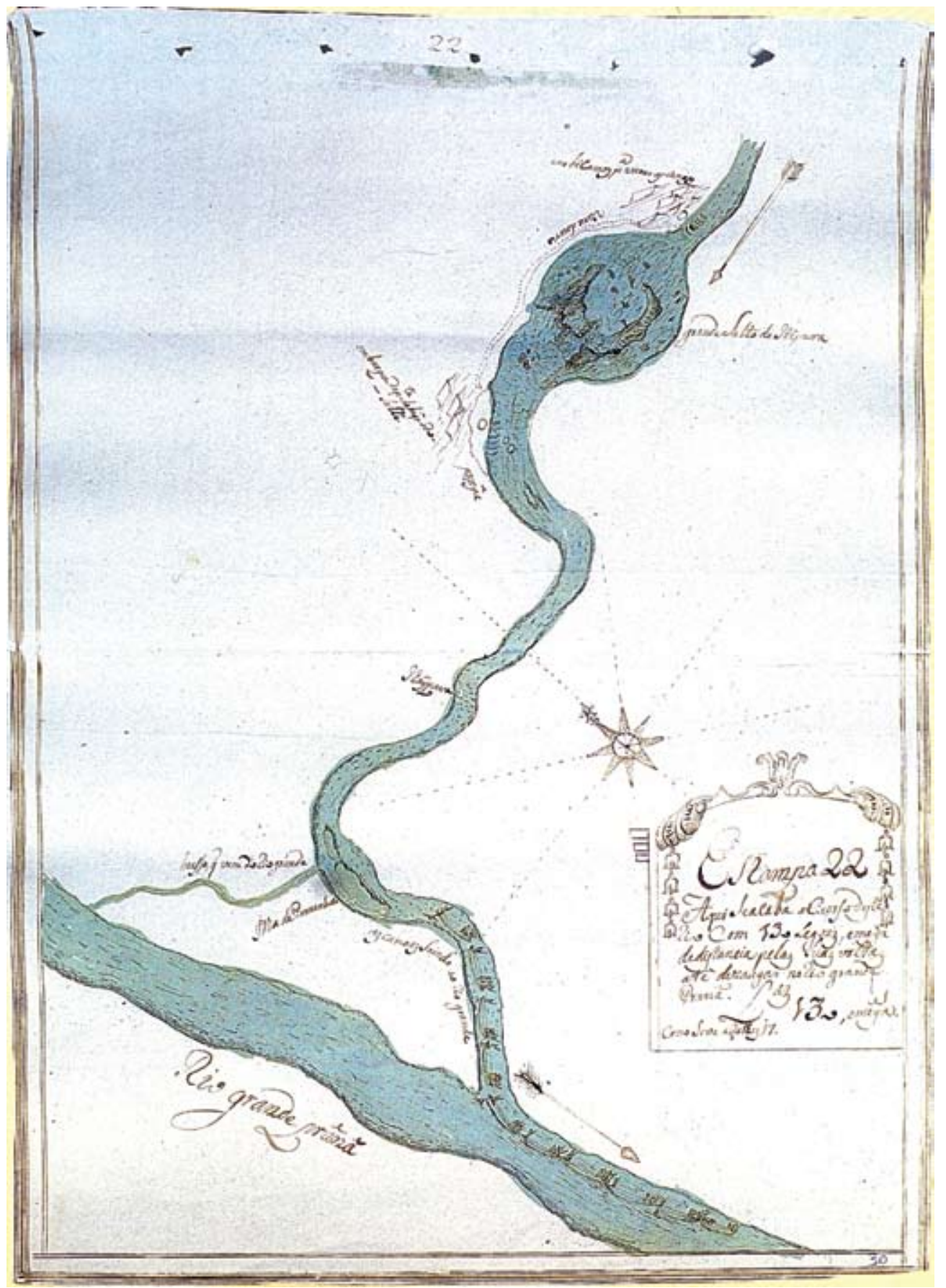

Figura 3 - Teotônio José Juzarte. Na parte de cima do prospecto, Juzarte desenhou o Salto de Itapura, que quer dizer "onde faz ponta a pedra grande", local em que as canoas vararam por terra; abaixo a seqüência de canoas sinaliza o percurso do rio Grande do Paraná. Aqui se acaba o curso desse rio com 130 léguas e meia de distância pelas suas voltas até desaguar no rio Grande do Paraná. [Dias 5, 6 e 7 de maio.], 1769. Fonte: SOUZA; MAKINO, 2000, p.393. 


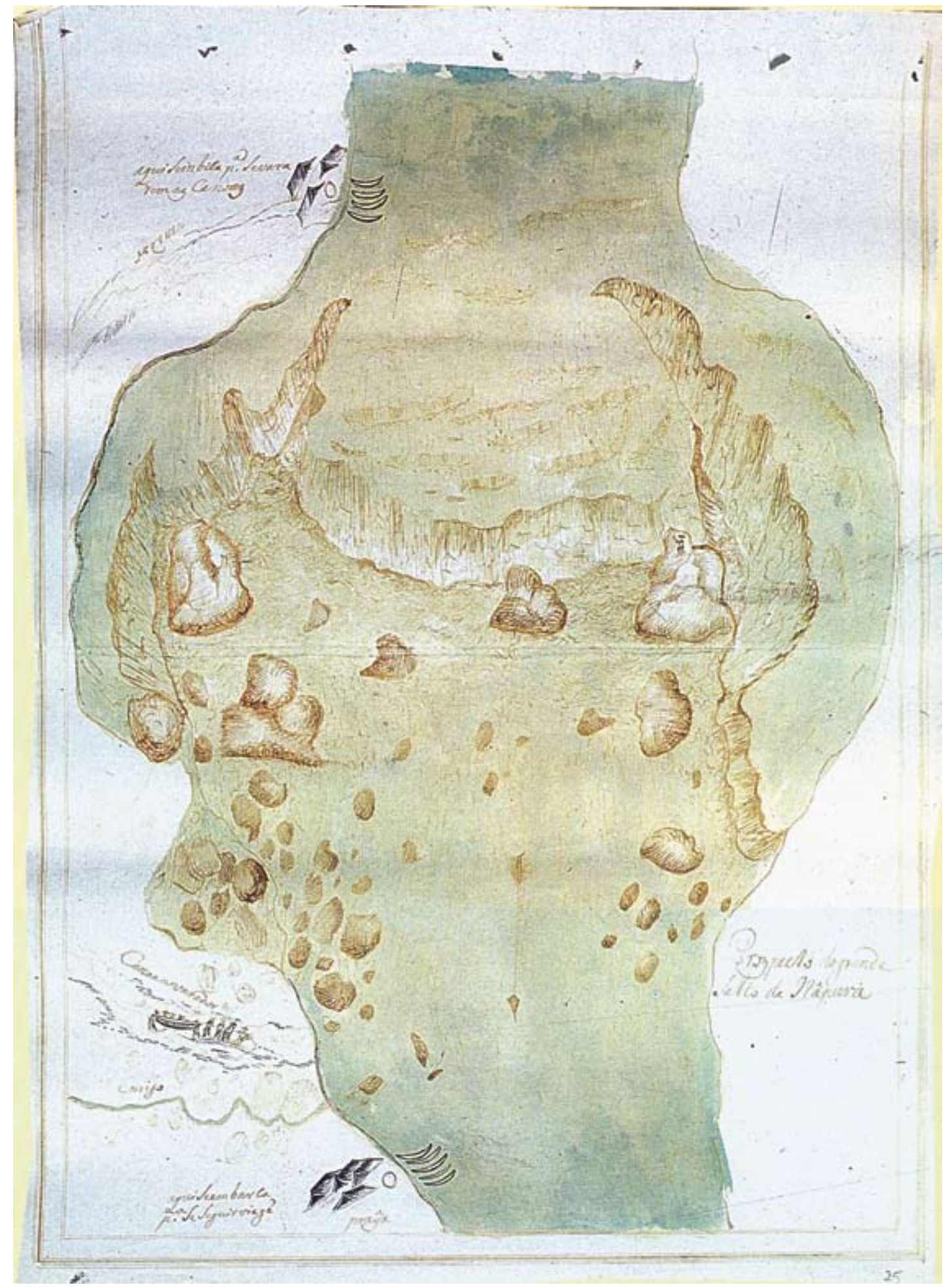

Figura 4 - Teotônio José Juzarte. Prospecto do Grande Salto de ltapura, 1769. Fonte: SOUZA; MAKINO, 2000, p. 394. 


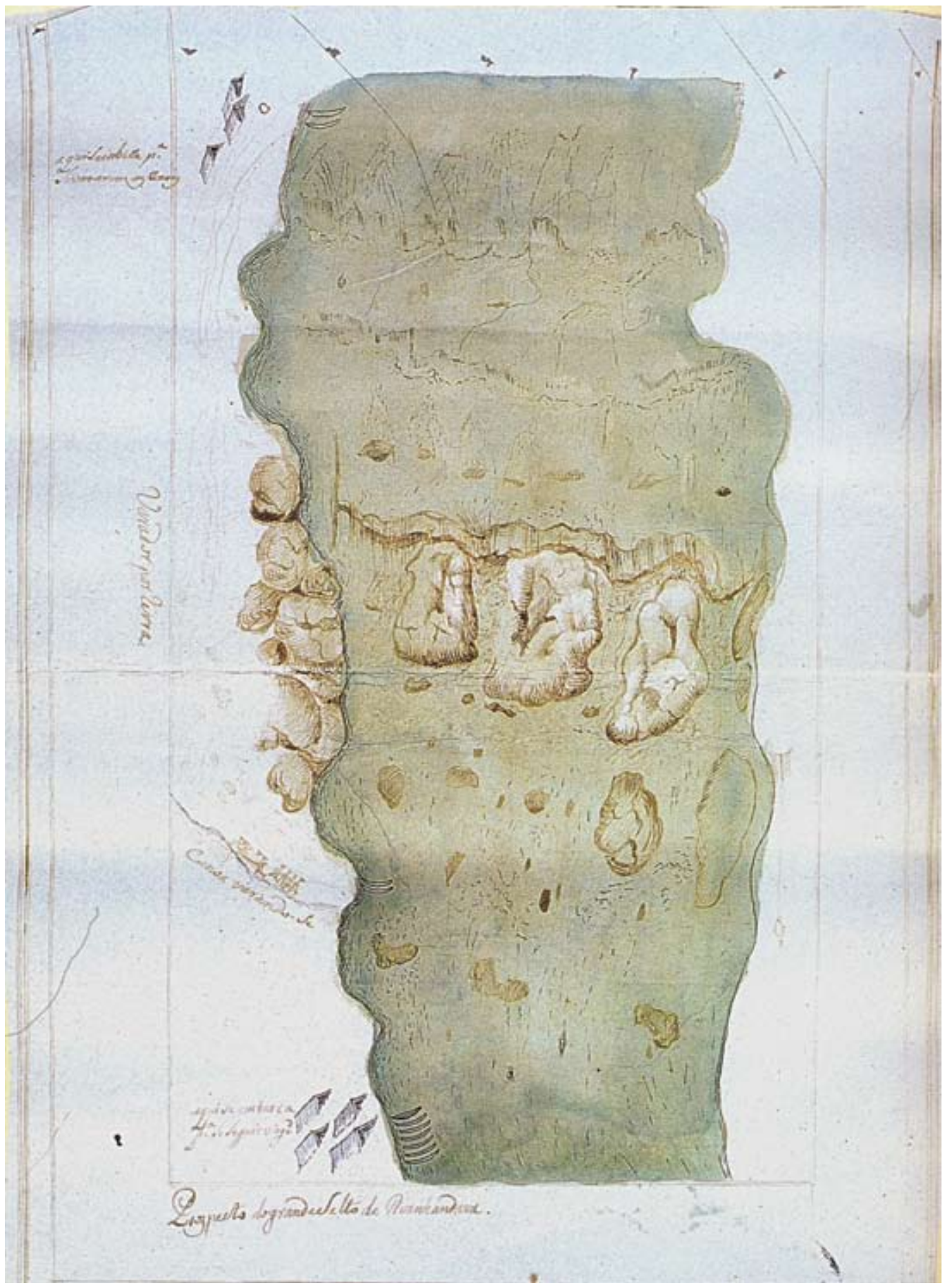

Figura 5 - No lado esquerdo, Juzarte assinalou o lugar onde as canoas embicaram em terra para passar pelo varadouro, com muito perigo e trabalho, e, abaixo, o lugar onde as canoas foram recolocadas no rio para seguir viagem. Teotônio José Juzarte. Prospecto do grande salto de Avanhandava, 1769. Fonte: SOUZA; MAKINO, 2000, p.385. 
63. Idem, p. 74 .

64. Leopoldinia pulchra, também denominada jará, jaraiuba ou jaraiuva.

65. Cf. Arquivo do Estado de São Paulo (1895, v. 43, p. 126).

66. Cf. Bárbara Belyea (1998, p. 141)
No dia 12 de julho de 1769, os povoadores finalmente aportaram à Praça de Nossa Senhora dos Prazeres do Iguatemi, ao fim de uma viagem perigosa, que durou dois meses e dois dias. Juzarte testemunha: "chegamos às sete horas da noite com muita alegria de todos dando muitos tiros correspondendo também da Praça com outros tantos de espingarda; chegamos ao porto do desembarque o qual é muito empinado, aí achamos o capitão João Alves Ferreira, que nos veio receber no barranco do rio; desembarcamos todos, e entramos na praça cada um se aquartelou como pôde"b3.

Mas a praça, isolada em meio ao território dos índios guaicurus, nada tinha a oferecer aos novos povoadores: construções inacabadas, uma igrejinha de taipa, sem ornamentos, coberta de "cascas" de palmito jarauba ${ }^{64}$, casas de taipa cobertas de capim, e terras estéreis onde viviam homens famintos. "Achava-se esta praça sujeita às suas próprias forças [que não era nenhuma]", comenta Juzarte. Vinte dias depois de o Tratado de Santo Ildefonso ter sido firmado em $1 .{ }^{\circ}$ de outubro de 1777, a Praça de lguatemi foi atacada por uma tropa de mais de três mil homens, entre espanhóis e índios guaicurus, Os povoadores regressaram ao porto de Araritaguaba "faltos de tudo"65.

\section{Considerações finais}

A abordagem cartográfica ameríndia nutria (e ainda nutre) um profundo conhecimento dos territórios, privilegiando, de um lado, o sentido das narrativas e, de outro, as representações detalhadas e precisas da geografia e da topografia do sertão, tais como o tamanho das montanhas, as formas dos lagos, as curvas, pedras e correntes dos rios, os locais de caça e de pesca, a classificação das árvores e das ervas, a localização das aldeias indígenas e assim por diante.

Segundo Bárbara Belyea, as direções espaciais (norte, sul, leste e oeste) são simplificadas e até mesmo ignoradas nos mapas ameríndios, porque a chave de leitura não se fixa em pontos localizados no espaço, mas traça um padrão contínuo de uma geografia a outra, como se fosse uma narrativa. É a intersecção, portanto, que determina o desenho cartográfico ${ }^{66}$.

Assim, ramificada na experiência, nos sentidos, na tradição, na memória e na narração - e tendo como características a transmissão oral e gestual, o sentido polissêmico do espaço, a preocupação com a forma e a representação do espaço feita em desenhos, bidimensionais ou tridimensionais, impressos sobre múltiplos suportes: areia, papel, pele, tecido, cipó, entre outros - a cartografia indígena, contribuiu de modo incisivo para que, durante os três primeiros séculos da colonização portuguesa, os paulistas conseguissem decifrar o sertão americano.

Agentes da colonização da capitania de São Paulo (bandeirantes, missionários, soldados, povoadores, burocratas, comerciantes e aventureiros) valeram-se, nos séculos XVI, XVII e XVIII, desse acervo cartográfico a fim de explorar 
as riquezas e expropriar os indígenas de seus territórios identificados ao sertão. Em tais mapas, acrescenta Alida Metcalf, "o sertão especificava o interior do Brasil, os territórios sob o controle dos índios e floresta virgem que poderia ainda existir em torno dos povoamentos portugueses e entre eles" 67 . Gregory Nobles ${ }^{68}$ sugere que, para melhor dominá-los no processo de conquista, os adventícios procuraram diminuir e até negar a presença dos índios em seus territórios.

No entanto, para Serge Gruzinski, a situação colonial impôs uma nova orientação do espaço que, devido à conjugação dos símbolos indígenas com os símbolos coloniais, favoreceu arranjos cartográficos inéditos ${ }^{69}$. Ao lado do mapeamento detalhado dos caminhos, rios, montanhas, serras, lagos, florestas e aldeias indígenas, emergiram os signos da colonização: fazendas, arraiais, vilas, fortes, presídios, minas de ouro, registros de quilombos e de aldeias indígenas, aliadas ou hostis.

Nos roteiros e mapas, a serviço da Coroa portuguesa, o espaço do sertão foi gradativamente ordenado, medido, delimitado e fixado. Os grupos étnicos que nele viviam foram tomados como unidades fechadas e homogêneas, portadoras de uma mesma língua e de uma mesma identidade. Nos mapas, alguns grupos indígenas figuram num território fixo, delimitado por referências da "civilização" ibérica (vilas, fazendas, missões, igrejas, fortes, minas de ouro). Na ordem colonial, analisa John Monteiro, cada grupo se constrói e é classificado em relação ao seu oposto, conforme as políticas de alianças e inimizades criadas no tempo da conquista, como Tupinambá e Tupiniquim, Tupi e Tapuia ${ }^{70}$. Na expressão de Miguel Alberto Bartolomé, as etnias ganharam "rótulos étnicos generalizantes"71, presentes nos mapas e roteiros do sertão, ao lado de representações vincadas nas narrativas indígenas.

\section{REFERÊNCIAS}

\section{FONTES IMPRESSAS}

ANTONIL, André João (pseudônimo). Cultura e opulência do Brasil [1711]. 2. ed. São Paulo: Nacional, [s. d.].

CARDIM, Fernão. Tratado de terra e gente do Brasil [1584]. Belo Horizonte: Itatiaia; São Paulo: Edusp, 1980.

DANIEL, João. Thesouro descoberto no maximo Rio Amazonas - Parte II. Revista do Instituto Histórico e Geográfico Brasileiro, Rio de Janeiro, v. 1/3, p. 39-500, 1860.

ÉVREUX, Yves d'. Viagem ao norte do Brasil feita nos annos de 1613 e 1614. Rio de Janeiro: Freitas Bastos; Livraria Leite Ribeiro, 1929.

FLORENCE, Hercules. Viagem fluvial do Tietê ao Amazonas: 1825 a 1829. Trad. Visconde de Taunay. São Paulo: Cultrix; Edusp, 1977.
67. Cf. Alida Metcalf (1996, p. 420).

68. Cf. Gregory H. Nobles (1977, p. 61).

69. Cf. Serge Gruzinski (2003, p. 71, 73).

70. Cf. John Monteiro (2001, p. 172).

71. Cf. Miguel Alberto Bartolomé (2006, p. 44). 
JUZARTE, Teotônio José. Diário da Navegação do rio Tietê, rio Grande Paraná, e rio Gatemi em que se dá relação de todas as coisas mais notáveis destes rios, seu curso, sua distância, e de todos os mais rios que se encontram, ilhas, perigos, e de tudo o acontecido neste diário pelo tempo de dois anos e dois meses. Que principia em 10 de março de 1769. Org. Joanas Soares Souza; Miyoko Makino. São Paulo: Edusp; Imprensa Oficial, 2000.

ARQUIVO DO ESTADO DE SÃO PAULO. Documentos interessantes para a história e costumes de São Paulo, v. 4; 22; 43. São Paulo: Tipografia Aurora; Arquivo do Estado, 1895.

RELAÇÃO da chegada que teve a gente de Mato Groço, e agora se acha em Companhia do Senhor D. Antonio Rolim desde o porto de Araritaguaba, até a esta Villa Real do Senhor Bom Jesus de Cuyabá (1754). Anais da Biblioteca Nacional, Rio de Janeiro, v. 20, p. 245-248, 1988.

SOUSA, Gabriel Soares de. Tratado descritivo do Brasil em 1587. 5. ed. São Paulo: Nacional; Brasília: Instituto Nacional do Livro, 1987.

TAUNAY, Affonso d'E. Na era das bandeiras. 2. ed. São Paulo: Melhoramentos, 1922a. . Uma expedição ao Iguatemi. Annaes do Museu Paulista, São Paulo, tomo I, 1922b. Relatos sertanistas. Belo Horizonte: Itatiaia; São Paulo: Edusp, 1981a. Relatos monçoeiros. Belo Horizonte: Itatiaia; São Paulo: Edusp, 1981 b.

\section{LIVROS E PERIÓDICOS}

BARTOLOMÉ, Miguel Alberto. As etnogêneses: velhos atores e novos papéis no cenário cultural e político. Mana, Rio de Janeiro, v. 12, n. 1, p. 39-68, abr. 2006.

BRUNO, Ernani Silva. Viagem ao país dos paulistas: ensaio sobre a ocupação da área vicentina e a formação de sua economia e de sua sociedade nos tempos coloniais. Rio de Janeiro: José Olympio, 1966.

CORTESÃO, Jaime. A fundação de São Paulo, capital geográfica do Brasil. Rio de Janeiro: Livros de Portugal, 1955.

. Raposo Tavares e a formação territorial do Brasil, Rio de Janeiro: Ministério da Educação e Cultura, 1958.

História do Brasil nos velbos mapas. Rio de Janeiro: Instituto Rio Branco do Ministério das Relações Exteriores, [1965?].

GRUZINSKI, Serge. A colonização do imaginário. Sociedades indígenas e ocidentalização no México espanhol, séculos XVI-XVIII. Trad. Beatriz Perrone-Moisés. São Paulo: Companhia das Letras, 2003.

KOK, Glória. O sertão itinerante. Expedições da capitania de São Paulo no século XVIII. São Paulo: Hucitec; Fapesp, 2004.

HOLANDA, Sérgio Buarque de. Monções. 3. ed. ampl. São Paulo: Brasiliense, 1990. Caminhos e fronteiras. $3^{\text {a }}$ ed., São Paulo: Companhia das Letras, 1994. 
Movimentos da população em São Paulo no século XVIII. Revista do Instituto de Estudos Brasileiros, São Paulo, n. 1, p. 55-111, 1996.

LÉVI-STRAUSS, Claude. O pensamento selvagem. 2. ed. Trad. Tânia Pellegrini. Campinas: Papirus, 1997.

LEWIS, Malcolm (Ed.). Cartographic encounters. Perspectives on native American Mapmaking and map use. Chicago: The University of Chicago Press, 1998.

MAGALHÃES, Basílio de. Expansão geográfica do Brasil colonial. 3. ed. Rio de Janeiro: Epasa, 1944.

MAPA: imagens da formação territorial brasileira. Pesquisa, textos e seleção cartográfica de Isa Adonias, Rio de Janeiro: Fundação Odebrecht, 1993.

METCALF, Alida. Vila, reino e sertão no São Paulo Colonial. In: AZEVEDO, Francisca L. Nogueira de; MONTEIRO, John Manuel (Orgs.). Raízes da América Latina. Rio de Janeiro: Expressão e Cultura; São Paulo: Edusp, 1996.

MONTEIRO, John Manuel. Os Negros da Terra: índios e bandeirantes nas origens de São Paulo. São Paulo: Companhia das Letras, 1994.

Tupis, tapuias e bistoriadores: estudos de história indígena e do indigenismo. Tese (Livre Docência) - Departamento de Antropologia, Instituto de Filosofia e Ciências Humanas, Unicamp, Campinas, 2001.

NOBLES, Gregory H. American frontiers: cultural encounters and continental conquest. New York: Hill \& Wang, 1977.

PETRONE, Pasquale. Aldeamentos paulistas. São Paulo: Edusp, 1995.

SAMPAIO, Teodoro. O tupi na geografia nacional. Revista do Instituto Histórico e Geográfico de São Paulo, São Paulo, v. 6, 1902.

SOUZA, Jonas Soares de; MAKINO, Miyoko (Org.). Diário de navegação - Teotônio José Juzarte. São Paulo: Edusp; Imprensa Oficial, 2000.

SOUZA, Laura de Mello e. O diabo e a terra de Santa Cruz: feitiçaria e religiosidade popular no Brasil colonial. São Paulo: Companhia das Letras, 1986a.

Os desclassificados do ouro. A pobreza mineira no século XVIII. 2. ed. Rio de Janeiro: Graal, 1986b.

.Formas provisórias de existência: a vida cotidiana nos caminhos, nas fronteiras e nas fortificações. In: SOUZA, Laura de Mello (Org.). História da vida privada no Brasil: cotidiano e vida privada na América portuguesa, 1. São Paulo: Companhia das Letras, 1997.

ZENHA, Edmundo. Mamelucos. São Paulo: Revista dos Tribunais, 1970.

Artigo apresentado em 8/2008. Aprovado em 3/2009.

Annals of Museu Paulista. v. 17. n.2. July - Dec. 2009. 